\title{
A VISÃO AMAZÔNICA DO PE. CRISTÓBAL DE ACUÑA: DA VIAGEM À INVENÇÃO DA AMAZÔNIA
}

\author{
Sandoval da Silva Mafra \\ sanmafra@hotmail.com
}

\begin{abstract}
Resumo: Este artigo tem por objetivo verificar e analisar os recorrentes discursos sobre a invenção da Amazônia, nos relatos dos primeiros viajantes europeus, dando ênfase às narrativas do Pe. Cristóbal de Acuña, já que a representação do espaço amazônico, desde essa época, é centrada na temática ambiental que invoca o imaginário do El Dorado prometido. Essa centralização nessa "floresta fantástica" torna "invisível" o discurso de uma Amazônia crescente e significativa para o latino-americano e o amazônico.
\end{abstract}

Palavras-chave: Discurso; Amazônia; Literatura de Viagem

\section{0 . INTRODUÇÃo}

Compreender o homem por meio do estudo da literatura de viagem, buscar as razões que o levam a viajar e descobrir ou, ainda, investigar como as viagens influenciam no seu comportamento, são questões importantes para se constatar quais os discursos que inventaram a Amazônia ao longo de sua história. Nesse sentido, a partir da análise dos relatos dos primeiros expedicionários europeus, que viajaram pelo Rio Amazonas, no século XVI, até as narrativas recentes, é possível perceber vários discursos que dão 
ênfase à representação amazônica pela temática ambiental, pela noção do exotismo: ora edênica, ora infernal. Discursos esses que fazem da região uma fonte de riqueza natural disponível para satisfazer as necessidades econômicas das nações estrangeiras. Sua grandeza natural enquanto apreensão coletiva é, portanto, uma invenção, termo utilizado por Neide Gondim (I994). Invenção esta construída por um olhar de fora para dentro. Uma visão que percebe a região enquanto floresta tropical maravilhosa, mas que negligencia ou inviabiliza o homem que nela habita.

Neste trabalho discutem-se mais especificamente os desafios em contrapor os discursos construídos pelas nações europeias para colonizar a Amazônia. É uma tentativa de superar o mito amazônico, simplificador e reducionista das diversidades e complexidades regionais. Inicialmente, delineia-se, a partir principalmente dos teóricos Álvaro Machado, Daniel-Henri Pageaux, Miriam Ávila e Silviano Santiago, as definições e as categorias de composição estética da literatura de viagem, enquanto um gênero híbrido. Em seguida, aborda-se o processo da invenção imaginário-discursiva da Amazônica, dando ênfase às especificidades históricas e culturais amazônicas, a ideia de sua invenção e mitificação. Para tanto, apoia-se em Neide Gondin e Ana Pizarro. Para finalizar, analisa-se o relato do Pe. Cristóbal de Acuña, que é o objetivo principal deste trabalho.

\section{A inVENÇ̃̃o IMAginÁRIO - Discursiva DA AMAZÔNIA}

Atualmente, os estudos e a compreensão dos textos e narrativas sobre a Amazônia, realizados pelas Ciências Humanas, a exemplo das Letras, Antropologia, História e Sociologia revelam que eles foram subsídios fundamentais, utilizados pelos europeus, para tramar, inventar e fixar imaginários e estereótipos sobre a região. A Amazônia é resultado de uma invenção por parte de políticas colonialistas europeias que visavam a encontrar o País das Canelas, à exploração das riquezas nela existentes, 
não se importando com os nativos que nela habitavam, conforme afirma Neide Gondim em A Invenção da Amazônia (1994):

[...] a Amazônia não foi descoberta, sequer foi construida; na realidade, a invenção da Amazônia se dá a partir da construção da Índia, fabricada pela historiografia greco-romana, pelo relato dos peregrinos, missionários, viajantes e comerciantes. [...] Inclui-se, ainda, a mitologia indiana que, a par de uma natureza variada delicia e apavora os homens medievais. A tal conjunto de maravilhas anexam-se as monstruosidades animais e corporais, incluídas tão somente enquanto oposição ao homem, considerado como Adamita normal e habitante de um mundo delimitado por fronteiras orientadas por tradiçôes religiosas. (Gondim, I994, p.o9).

É a partir desses discursos que a Amazônia começa a ser inventada, pois as primeiras viagens ao Novo Mundo fizeram-se acompanhar por esse imaginário fantástico e influenciaram a visão do europeu sobre as terras jamais vistas. Para os expedicionários europeus, o lugar recém-descoberto era o Paraíso, onde, para tradição religiosa, existia a fonte da eterna juventude e a supressão de todos os males sociais. Neste sentido,

o tema da localização do paraíso e do inferno é frequente nos relatos dos viajantes [...] A fauna e a flora extraordinárias, os lugares sagrados das histórias biblicas também foram constitutivos da construção do imaginário. A água miraculosa que impedia o envelhecimento e a fartura de ouro e pedras preciosas acalentaram o sonho de gerações de ter riquezas sem desgaste físico e viver eternamente. As monstruosidades corporais - homens ou animálias e ainda as mulheres solitárias, as Amazonas e a raça de gigantes - eram temas recorrentes nesse arcabouço imagistico, que não se encerra com o descobrimento da América [...]. (Gondim, op. cit., p.34).

Defendendo a certeza de ter encontrado o Paraíso Perdido, Colombo desencadeia, com as suas expedições, o alargamento das fronteiras do 
então denominado Mundo Novo. Com a chegada do viajante espanhol às Antilhas se intensifica um ciclo de conquistas, descobertas, conflitos, barbárie, mortes, invenções, das quais a Amazônia é um dos desdobramentos e, assim, a região surge no cenário mundial. No entanto, O El Dorado parecia indiferente para os exploradores, pois os costumes, a organização social e política dos nativos, que nele habitavam, eram diferentes dos europeus, constituindo-se, assim, essas diferenças, em relatos que refletem o discurso dominante do colonizador. Deste modo,

[...] o novo éfiltrado pelo antigo, assegurando a este sua supremacia. A prática de comparar as novidades vistas pela primeira vez com o pretensamente conhecido, sendo domesticado, fortalecerá e documentará a estabilidade do antigo. Não é só o mundo antigo que se projeta, assim, sobre o novo: é o mundo de casa que se anexa pacificamente sobre os descobrimentos ultramarinos [...]. (Gondim, 1994, p.38).

Assim, a invenção da Amazônia proposta por Gondim (1994) advém dos discursos das narrativas oficiais, daqueles que estavam a serviço da coroa portuguesa e espanhola em terras desconhecidas. No caso da Amazônia, o nativo é visto pelos colonizadores como um "bárbaro", em virtude da prática nativa da antropofagia. Deste modo, "a preguiça será também usada como uma das justificativas da empresa colonialista em terras brasileiras amazônicas, vista como um dos entraves de transformação regional. Trará a idéia da inferioridade racial do norte brasileiro". (Gondim, op. cit., p.57).

Por serem indiferentes às riquezas existentes na região, os nativos eram vistos pelos europeus como indolentes e desinteressados pelo traba1ho, pelo comércio e pelo processo civilizatório, sendo considerados como um grande problema aos avanços para a conquista da terra. Por isso, "os nativos são os agentes que desarmonizaram a ordem social instalada pelo branco. Essa é a conclusão a que praticamente todos os viajantes chegaram depois de visitar o paraíso infernal amazônico". (Gondim, op. cit., p.I33). 
Esses discursos criam uma nova tradição, revigorando o que veio antes, constituindo um novo que se aprofunda e cria raízes na memória. São vestígios inconscientemente conservados e reproduzidos, como também associações culturais escritas socialmente, reflexo do imaginário europeu sobre o desconhecido. De acordo com a pesquisadora chilena Ana Pizarro:

La Amazonia es una construcción discursiva. Es nuestra tesis. No se ha llegado a ella sino a través de esta construcción. Es la historia de los discursos que la han ido constituyendo en diferentes momentos históricos y de los cuales hemos recibido parte de la información, fundamentalmente la que permite identificar el discurso externo sobre ella [...] La Amazonía como espacio físico y humano, cultural, tenía elementos que actuaban como dispositivos simbólicos en el ocupante, gatillándole conexiones semióticas del imaginario, permitiéndole construir com lo que veía um universo mitico, que respondia a sus carencias, expectativas, necesidades físicas y espirituales [...]. (Pizarro, 2005, p.I34).

Nesse sentido, o resultado disso foi a elaboração de textos com elementos incomuns, cujas relações representaram as configurações dos imaginários da sociedade europeia, em determinadas condições de existência. Esse discurso constituiu um corpus a partir da interação do novo ocupante, o europeu, com o antigo, o nativo da Amazônia. No entanto, esse discurso não era inocente, "venía cargado de un punto de vista, de uma historia y de las necesidades de ésta. Cargado pues, de fantasias. Su efecto sobre el medio fue sin embargo determinante para lo que sería el futuro de este espacio geográfico y sus sociedades". (PizArro, op. cit., p.I34).

A maioria desses textos foi produzida por missionários, especialmente portugueses e espanhóis, que documentaram informações essenciais para a colonização da Amazônia. Entre eles está o relato do Pe. Cristóbal de Acuña, religioso da Companhia de Jesus, denominada de o Novo 
descobrimento do rio das Amazonas, escrito em I639, o qual será o corpus analisado neste artigo.

\section{Pe. Cristóbal de Acuña: relato de viagem, visões amazônicas}

Segundo Acuña,

[...] se o lago Dourado tem o ouro que a opinião geral lhe atribui, se as amazonas habitam, como testemunham muitos, entre as maiores riquezas do planeta; se os Tocantins são tão afamados pelos franceses pelas pedras preciosas e abundância de ouro; se os Omáguas com suas possessões alvoroçaram o Peru e logo o vice-rei despachou Pedro de Ursúa com um grande exército para tentar descobri-los, neste Grande Rio está tudo encerrado: o lago Dourado, as amazonas, os Tocantins e os ricos Omáguas [...] Nele, finalmente, está depositado o imenso tesouro que a majestade de Deus tem guardado para enriquecer, com ele, a de nosso grande rei e senhor Felipe Quarto. (Acuña, I994, p.I03).

Com esse discurso fantasioso sobre a Amazônia, inaugura-se discursivamente aquela que viria a ser uma das mais importantes e cobiçadas regiões do planeta. Para os espanhóis, a conquista do Paraíso, onde se localizava o Grande Rio, era, sem dúvida, um amplo investimento comercial e catequizador que, em nome do Rei e de Deus, lhes renderiam riquezas e expansão do Cristianismo.

Segundo Esteves (1994) o objetivo de Acuña era fazer um relatório completo de tudo o que visse durante a viagem, informando com maior clareza possível as riquezas existentes na região, além de descrever a geografia e as populações locais. Mas, para isso, ele se apoiará em informações de textos escritos anteriormente por outros missionários como, por exemplo, Gaspar de Carvajal, Alonso de Rojas, entre outros, constituindo-se nas chamadas Relaciones. 
As chamadas Relaciones faziam parte de um conjunto de textos com o objetivo de relatar ou informar oficialmente, por ordem da Coroa Imperial. Já as cartas, crônicas e outros gêneros eram modelos clássicos de escrita e seguiam certa tradição discursiva. Neste sentido, as Relaçôes atendiam aos imperativos do momento específico da Conquista, baseando-se nas necessidades de informações para certas circunstâncias e lugares.

Os discursos produzidos nas Relaciones deveriam obedecer a uma estrutura formalmente definida, determinando o que devia ser objeto de interesse. Percebe-se, em alguns momentos, no texto de Acuña, que o ato de escrever tinha como objetivo um duplo referencial: a realidade vivida, que autoriza os sujeitos do discurso a afirmar a verdade de suas anotações, e o corpo integrado pelo conjunto de obras anteriores.

Nesse sentido, o Novo Descobrimento do Rio Amazonas dialoga várias vezes com as obras de Gaspar de Carvajal e de Alonso de Rojas. Reitera, por exemplo, as afirmações que testemunhavam a densidade populacional da várzea, o tamanho dos povoados que se distribuíam ao longo dela, entre outros fatos. Mesmo que houvesse uma redução da população indígena ao longo do primeiro século de colonização, Acuña registra, ainda, a presença de uma considerável população às margens do rio, descrevendo-a, até certo ponto, de maneira preconceituosa, como se observa em seu enunciado:

Todo este novo mundo [...] está habitado por bárbaros de variadas provincias e nações, das quais posso dar boa fé, enumerando-as por seus nomes e indicando sua localização, algumas de vista e outra por informações de indios que nelas estiveram. Passam de cento e cinquenta, todas de linguas diferentes, tão extensas e ocupadas por moradores como as que vimos por todo o trajeto [...]. (AcuÑA, op. cit., p.Io5-106).

Ao contrário da experiência de Orellana e de seus homens, que foram açoitados por nativos agressivos, as referências do jesuíta Cristóbal de Acuña aos indígenas são de que "nenhum tem para com o espanhol ati- 
tude hostil, como se notou em toda viagem, na qual nenhum bárbaro jamais se atreveu a usar contra nós, outra defesa além daquela que usam os covardes prevenidos, que é a fuga". (Acuña, op. cit., p.Io7). A constatação pode refletir o fato de os combates anteriores terem ensinado os nativos da região sobre a dificuldade em combater os europeus e que a retirada seria a melhor estratégia a ser adotada.

As apreciações do padre espanhol sobre os indígenas são frequentemente "delicadas" quando afirma que é gente pacífica, de boa índole e adaptada ao ambiente em que vivem com fartura e bonança. Entre outras coisas, mereceram sua atenção as ferramentas e armas que usavam, na guerra e na caça, os procedimentos para fazerem suas bebidas, práticas de pesca e aprisionamento de tartarugas em armadilhas, além das redes de trocas que se estabelecem, pela água, entre várias aldeias, incluindo bens de prestígio e bens de uso, como a cerâmica ou os tecidos. Tal como se esperava de um texto da natureza de Relação, o autor apresenta muitas informações sobre os nativos, corpus cuja importância cresce à medida que muitos destes grupos vieram a desaparecer fisicamente nas décadas seguintes.

Além disso, há ainda dados importantes que não se referem ao âmbito da cultura material, como os ritos de hospitalidade, as práticas funerárias, "ídolos" e "feiticeiros". Acuña reconhece a "malícia" nas ações dos feiticeiros e se vale de adjetivações preconceituosas para com esses chefes nativos, como se observa no trecho de seu relato:

Do mesmo modo que o anterior, ainda que com maior malícia, mostrou-se outro bárbaro, o qual, não reconhecendo nem poder nem deidade em seus ídolos, ele mesmo se fazia de deus de toda aquela terra. [...] Têm os feiticeiros, para usar em suas superstiçôes e para falar com o demônio, o que é muito frequente, uma casa que só serve para isso. Ali [...] eles vão recolhendo todos os ossos dos feiticeiros que morrem, os quais mantêm dependurados nas mesmas redes em que dormiam em vida. Eles são seus mestres, seus predicadores, seus conselheiros, seus guias [...]. (ACUÑA, op. cit., p.II5-II7). 
Mas, em certos momentos, revela-se um observador "sensível" ao relatar, em certa ocasião, o modo como os índios cativavam os seus escravos, percebendo que o valor dado a eles era outro, não apenas o econômico, e que as relações travadas neste particular diferiam daquelas conhecidas no Ocidente, conforme o padre jesuíta relata:

Dos escravos que estes Águas cativam em suas batalhas, servem-se para tudo o que for necessário, tendo-lhes tanta afeição que, com eles, comem no mesmo prato. Tentar fazer com que os vendam é algo que eles sentem muito, como por experiência vimos em várias ocasióes. Chegávamos a um povoado destes indios e eles nos recebiam não apenas com manifestações de paz, mas também com danças e grande alegria e ofereciam o que tinham, para nosso sustento, com grande boa vontade [...]. (ACUÑA, op. cit., p.r37).

De acordo com Esteves (1994), embora Acuña tivesse a orientação explícita de fazer um levantamento de toda a região percorrida, não conseguiu fazê-lo. Ao realizar, um século mais tarde, a mesma viagem feita por Orellana, ele acabou repetindo algumas lendas, embasando-se apenas nas informações das viagens anteriores e no que lhes disseram os nativos. Praticamente se assenta na autoridade do texto escrito por Carvajal, como pode ser percebido quando o jesuíta refere-se às amazonas:

Os fundamentos que há para assegurar a existência da provincia das amazonas neste rio são tantos e tão fortes que seria faltar com a fé humana não lhes dar crédito [...] Só lanço mão do que ouvi com meus próprios ouvidos e com cuidado averiguei desde que colocamos o pé neste rio [...] Têm estas mulheres varonis seu assentamento entre grandes montes e eminentes cerros [...] o que mais se destaca [...] São as amazonas mulheres de grande valor, que sempre se têm conservado sem contato comum com varões e mesmo quando estes [...] vêm a cada ano a suas terras $[. .$.$] recebem-nos por hóspedes naqueles poucos dias [...] repetindo todos$ 
anos esta viagem na mesma época. As filhas que desta união lhes nascem elas conservam e criam entre si, que são as que levarão adiante os valores e costumes de sua nação, mas os filhos não há muita certeza do que com eles fazem. (AcuñA, op. cit., p.I77-I8I).

Embora Acuña repita alguns episódios fantásticos já relatados por outros escritores, procura seguir a linha do espírito racionalista dos jesuítas para ser o mais exato possível, utilizando-se, porém, como era usual na época, de uma linguagem erudita.

Entre outros mitos já relatados em viagens anteriores, o mito do Lago Dourado é bem enfatizado por Acuña, detalhando a localização geográfica do lugar e as riquezas nele existentes, embora o padre tenha o cuidado de não afirmar nada com certeza, colocando nas mãos de Deus o esclarecimento do mistério, conforme se pode observar no texto abaixo:

A vinte léguas do rio Tapi, deságua no Amazonas o rio Catuá [...]; leva vantagem, pela multiplicidade de nações, outro rio [...] com o nome de Araganatuba, seis léguas mais baixo [...] Entre essas nações, todas falando diferentes linguas, de acordo com as notícias que pelo Novo Reino de Granada correm, estáo desejado Lago Dourado, que mantém tão inquietos os ânimos de toda a gente [...]. Não afirmo por certo, mas algum dia queira Deus que saiamos desta perplexidade. [...] A vinte e duas léguas [...] termina a rica e populosa nação dos Curuzinari, habitantes de uma das melhores porções de terra que em todo este Grande Rio encontramos. (AcUÑA, op. cit., p.I5I).

Assim, no decorrer de seus relatos, o Pe. Cristóbal de Acuña não apenas repete o imaginário de outros escritores anteriores como, por exemplo, o de Carvajal, como também acrescenta novas informações de criaturas fantásticas. Acuña ressalta ter ouvido os índios falarem na existência de gigantes à margem do rio Cuchiguará. Mesmo só tendo ouvido falar dos homens grandes, utiliza-se de argumentos surpreendentes, que geram 
imagens monstruosas da Amazônia, tornando-a cada vez mais exótica e fantástica para Coroa Espanhola:

[...] desemboca na margem sul um famoso rio que os indios chamam de Cuchiguará [...] Está povoado por várias nações, que [...] são as seguintes: Cuchiguará, que tomam seu nome do rio, Cumayari, Guaquiari, Cuyariyayana, Curucuru, Quatausi, Mutuani e, por fim e remate de todos, estão os Curigueré. De acordo com informações de pessoas que os viram e que se ofereciam a levar-nos a suas terras, são eles gigantes de dezesseis palmos de altura, muito valentes, andam nus e trazem grandes patenas de ouro nas orelhas e narizes. Para chegar a suas aldeias são necessários dois meses contínuos de viagem desde a boca do Cuchiguará. (AcuÑA, op. cit., p.r55).

Enfatizando ainda mais uma Amazônia maravilhosa, cheia de encanto e magia, o jesuíta relata a existência, no território dos índios Tupinambás, de uma tribo de anões e outra de estranhos indígenas que possuem os pés ao contrário. Esses fatos eventualmente se assemelham às lendas que descreviam o mundo maravilhoso oriental, narrado nas viagens de Marco Pólo, já que o imaginário desses missionários estava impregnado desse pensamento medieval, conforme se pode observar nos trechos do texto do Pe. Cristóbal de Acuña:

[...] ...Estes indios Tupinambás ...são gente de mais civilização e que não necessitam de intérprete por ser corrente entre eles $[. .$.$] a lingua geral que muitos$ dos próprios portugueses falam com eloquência [...] Dizem eles que próximo a sua terra, pela parte sul, em terra firme, vivem, entre outras, duas naçöes: uma de anões tão pequenos como crianças muito novas, que se chamam Guayazi; a outra de uma gente em que todos têm os pés ao contrário, de modo que aqueles que, não os conhecendo, queira seguir seu rastro, caminhará sempre ao contrário deles. Chamam-se estes Mutayu (Acuña, op. cit., p.I75). 
No entanto, quando Acuña se refere à existência de seres fantásticos, percebe-se a utilização de um discurso com pouca rigidez. $\mathrm{O}$ jesuíta limita-se apenas a relatar que reproduz informações fornecidas pelos índios com quem teve contato ou de quem os ouviu falar. Contudo, antes de anotar as notícias que lhe dão os Tupinambás sobre os Guayazi e os Mutayu, informa que os Tupinambás são gente de mais civilização, persuadindo o leitor a dar-lhes credibilidade.

Além do mais, Acuña esclarece, ainda, um fato relevante: que não é necessário intérprete para falar com os Tupinambás, pois eles falam a língua geral comum a todos os nativos da Amazônia, falada pela maioria dos portugueses e por todos os mestiços. Coloca em xeque uma questão um pouco confusa em Carvajal: o problema da comunicação entre os nativos e exploradores. Pois, no texto do dominicano, não se tem idéia de como ocorria a comunicação com os nativos, apesar de ele ressaltar a facilidade que Orellana tinha para aprender as línguas indígenas. No entanto, nessa questão, ainda é interessante apontar a contribuição do relato de Acuña para o uso da língua geral, língua de mediação usada pelos padres jesuítas no Brasil para facilitar a comunicação entre clérigos e nativos, de modo a potencializar as estratégias de aculturação da empresa colonial.

Ao longo do relato de Acuña, podem-se destacar duas ideias capitais que cruzam sua obra: a necessidade de ocupação efetiva do território pela Espanha, para deter o avanço português e o aumento da presença de religiosos para atuarem na catequização dos indígenas que viviam "miseráveis à sombra da morte”. (AcuñA, op.cit., p.I9). Ambas as preocupações aparecem frequentemente associadas, pois o jesuíta critica duramente as estratégias empregadas pelos lusitanos para cativar escravos índios por meio da "guerra justa":

[...] Tal coisa costumam fazer os portugueses entre os gentios, não com tão bom zelo como a ação demonstra em si, servindo-lhes o santo madeiro da cruz, levantado em alto titulo e capa, para disfarçar suas maiores injustiças, como a continua 
escravização dos pobrezinhos indios que, como mansos cordeiros, são levados em rebanhos a suas propriedades, para vender alguns deles e servir-se com todo o rigor dos outros. (AcuÑA, 1994, p.II3).

O discurso de Acuña está claramente inserido na disputa pela Amazônia, como espaço de conquista e de missão catequizadora, debate em que se enfrentavam as ordens religiosas e os demais agentes da colonização interessados em mão-de-obra e "drogas do sertão".

O jesuíta questiona, também, as ações de apresamento feitas pelos lusitanos. Ele não apenas critica a cobiça com que se lançam à busca de escravos, como o tratamento dispensado aos presos e o desrespeito às mulheres, chegando até a denunciar a hipocrisia que se escondia sob o procedimento legal da chamada "guerra justa":

E que ninguém diga que o fato de estes indios não quererem vender seus escravos seja porque os têm para comê-los em suas bebedeiras, como dizem sem fundamento os portugueses, que andam metidos neste negócio e com isto querem encobrir sua injustiça [...]. Não quero negar, com isso, que haja neste rio gente canibal, que em ocasiões não têm horror de comer carne humana [...]. O que quero convencer é de que não existem em todo este rio açougues públicos, onde o ano todo se pesa carne de indios, como propalam aqueles que, argumentando querer evitar semelhante crueldade, praticam crueldades ainda maiores, transformando, com seus rigores e ameaças, em escravos aqueles que não o são. (AcuñA, op. cit., p.I37).

Em seu discurso, Acuña faz transparecer, para além das tradicionais rivalidades das Coroas Ibéricas nos seus territórios coloniais americanos, na ação dos lusitanos, especialmente dos capturadores de escravos índios, uma sensibilidade para com os jesuítas. É visível que, entre os discursos proferidos por Acuña, o mais delicado seja aquele que trata da relação com as sociedades indígenas, pois sabia que, em suas áreas, havia bastantes minérios. 
Acusando a pouca atenção e cuidado que a região vinha merecendo por parte das autoridades espanholas, ele assim exalta as potencialidades do rio Amazonas:

O famoso Rio das Amazonas atravessa e banha as mais ricas, férteis e povoadas terras de todo o império do Peru. É o que, de hoje em diante, podemos, sem usar hipérboles, qualificar como o maior e mais célebre do orbe. [...] Rega reinos mais extensos, fecunda mais veigas, sustenta mais homens e aumenta, com suas águas, o mais caudaloso oceano. [...] Do Rio das Amazonas pode-se afirmar que suas margens são o paraíso em fertilidade e, se a costa ajuda a fecundidade do solo, será todo ele um conjunto de apraziveis jardins. [...] (AcuÑA, op. cit., p. 75).

Observa-se que, no Novo Descobrimento do Rio Amazonas, Cristóbal de Acuña faz a descrição dos rios e das tribos de modo bem familiar aos olhos de seus leitores contemporâneos. Talvez ele utilize esse artifício como uma forma de persuadir o leitor e também para facilitar a reconstituição da obra, no caso de ela se perder no tempo. Sua Relación apresenta um imenso conjunto de dados sobre a geografia da região, a fauna, a flora, os costumes indígenas e as riquezas minerais.

Deste modo, a narrativa de viagem de Acuña, se levarmos em consideração o fato de ser ela um desdobramento das primeiras viagens, pode ser vista como um texto simbólico que traz ao leitor significativas representações e imagens sobre diferentes aspectos da vida do habitante da Amazônia. Além disso, revela as estratégias de defesa dos nativos em face dos espanhóis, a organização política das várias províncias nativas que viviam às margens dos rios amazônicos, os rituais religiosos praticados pelas diferentes etnias, a gastronomia, a habitação, as guerras entre as tribos, além dos diferentes artefatos artísticos produzidos por eles no interior da floresta.

Encarado como um grande feito pela Coroa Espanhola, o relato do Pe. Cristóbal de Acuña repercutiu positivamente na Europa do século 
XVIII. A referência à existência, por exemplo, de uma sociedade de mulheres sem marido, as amazonas, e a possível existência do Lago Dourado, estimulou a sociedade europeia a patrocinar outras expedições a fim de descrever e explorar as riquezas existentes na Amazônia. Assim, o relato de viagem do Pe. Cristóbal de Acuña é considerado um texto emblemático, cujos desdobramentos resultaram na invenção da Amazônia como uma fantástica região edênica e infernal, mas apreciada, na atualidade, como a região de maior biodiversidade do planeta.

Além do mais, o texto de Acuña construiu um referencial legitimamente europeu, um mito de origem ocidental para os habitantes do $\mathrm{Pa}$ raiso, cujo território incluiria, mais tarde, além da Amazônia brasileira, parte do Peru, Bolívia, Venezuela, Colômbia, Equador, Suriname, Guiana e Guiana Francesa. Entretanto, todos esses países, tendo um pedaço da Amazônia como parte de seus territórios nacionais, forjam seus imaginários e constituem suas identidades nos elementos da natureza: nas águas, nos igapós, nas lagoas, nos rios, na mata e nos animais. Assim, o colonizador tentou apagar os referenciais simbólicos mais preciosos do nativo: sua língua, seu sistema religioso de base ritualística e sua relação diferenciada e respeitosa com a terra.

\section{Considerações Finais}

A partir dos relatos dos primeiros viajantes, e, em especial, o analisado neste artigo, compreendeu-se que os discursos proferidos sobre a Amazônia, tanto pelos espanhóis quanto pelos portugueses, têm o intuito de descrever para a União Ibérica as riquezas existentes nas terras desconhecidas e garantir grandes investimentos para as colônias para ocupar a região sob seu domínio. Nesse sentido, ao longo de seu percurso histórico, a Amazônia vem sendo inventada a partir de um discurso dominador 
imposto por outras nações, produzido em nível de instituições comerciais, religiosas ou políticas.

\section{Bibliografia}

Acuña, Christóbal de. Novo Descobrimento do Rio Amazonas. Edição, tradução e introdução: Antônio R. Esteves. Edição bilíngue. Coedição: Consejería de Educación de la Embajada de España en Brasil. Asesoría Linguistica. Oltaver S.A. Buenos Libros Activos. Uruguay, I994.

Ávila, Myriam. Peripatografias: considerações sobre o motivo da viagem na literatura latino-americana, a partir de Héctor Libertella. In: Maciel, Maria Esthér et alli. América em movimento: ensaios de literatura latino-americana no séc. xx. Rio de Janeiro: Sette Letras, I999, p. II3-I2I.

Fernandes, José Guilherme dos Santos. Literatura brasileira de expressão amazônica, literatura da Amazônia ou literatura amazônica? In: Revista da Pós-Graduação em Letras - Uғ PB, João Pessoa, vol. 6., N. 2/I, 2004 - p.III-II6.

Gondin, Neide. Como o mar de águas doces e suas dilatadas províncias são percorridos pelo imaginário dos cronistas viajantes. In: A invenção da Amazônia. São Paulo: Marco Zero, I994, p. 77-г38.

Machado, Álvaro Manuel; Pageaux, Daniel-Henri. Identidade nacional e orientações estrangeiras. In: Da literatura comparada à teoria da literatura. Lisboa: Edições 70, 198I, p.I7-3I.

As experiências da viagem. In: Da literatura comparada à teoria da literatura. Lisboa: Edições 70, 1981, p.33-51.

Marques, José. Peregrinos e peregrinações medievais do ocidente peninsular nos caminhos da Terra Santa. 
Pizarro, Ana. Imaginario y discurso - La Amazonía. In: Sentidos dos lugares /organizadores José Luís Jobim... [et al.]. - Rio de Janeiro: ABRALIC, 2005, p. I3O-I52.

Santiago, Silviano. O entre-lugar do discurso latino-americano. In: Uma literatura nos trópicos. $2^{\text {a }}$ Ed. - Rio de Janeiro: Rocco, 2000, p. 09-26. O cosmopolitismo do pobre: crítica literária e crítica cultural. - Belo Horizonte: Editora UFMG, 2004.

Steinbrenner, Rosane A. "Amazônia" na Fronteira entre a Ciência e a Midia: Submissão ou Superação do Mito? Trabalho apresentado no viI Encontro dos Núcleos de Pesquisa em Comunicação - NP Comunicação Científica - xxx Congresso Brasileiro de Ciências da Comunicação. Núcleo de Altos Estudos Amazônicos (NAEA) - Ufpa.

Triceversa - Revista do Centro Ítalo-Luso-Brasileiro de Estudos Linguísticos e Culturais. - TriceVersa, Assis, v.I, nº.I, mai.-out. 2007.

Todorov, Tzvetan. A conquista da América: a questão do outro. Tradução Beatriz Perrone Moisés. - $2^{\text {a }}$ ed. - São Paulo: Martins Fontes, I999.

RESUMEN: Éste artículo tiene por objetivo verificar y analizar los recurrientes discursos sobre la invención de la Amazônia, en los relatos de los primeros viajantes europeos, dando ênfase a narrativas del Pe. Cristóbal de Acuña, ya que la representación del espacio amazónico, desde esa época, es centrada en la tematica ambiental que invoca el imaginario del El Dorado prometido. Esa centralidad sobre la "floresta fantástica" torna "invisíble" el discurso de una Amazonía creciente y significativa para el latino-americano y amazónico.

Palabras-llave: Discurso; Amazonía; Literatura de Viaje 